\title{
Extracorporeal Membrane Oxygenation Therapy for Aspiration Pneumonia in a Patient following Left Pneumonectomy for Lung Cancer
}

\author{
Jangwhan Jo, M.D. ${ }^{1}$, and Yang Gi Ryu, M.D. ${ }^{2}$ \\ ${ }^{1}$ Department of Trauma Surgery, ${ }^{2}$ Department of Thracic and Cardiovascular Surgery, Korea University Guro Hospital, Seoul, Korea
}

\begin{abstract}
A patient had undergone left pneumonectomy for lung cancer and had an increased risk of fatal complications such as pneumonia, including acute respiratory distress syndrome (ARDS). The treatment effects of veno-venous extracorporeal membrane oxygenation (VV-ECMO) for ARDS of postpneumonectomy patient are uncertain. A 74-year-old man with one lung experienced aspiration pneumonia while swallowing pills after the operation, and his condition progressed to ARDS within a day. He was successfully treated with V-ECMO support and intensive care unit care.
\end{abstract}

Key Words: aspiration pneumonia; extracorporeal membrane oxygenation; pneumonectomy; respiratory distress syndrome.

Acute lung injury and acute respiratory distress syndrome (ARDS) from aspiration pneumonia can lead to severe hypoxemia, disability in pulmonary function, and increased mortality rates from (increase from 30\% to 60\%).[1-3] Veno-venous extracorporeal membrane oxygenation (VV-ECMO) can be used to treat acute severe respiratory failure that does not respond to mechanical ventilator support. However, ARDS in a patient who has undergone pneumonectomy for lung cancer may not resolve with VV-ECMO. The risk of mortality and morbidity from ARDS is greater in pneumonectomy patients than in those who undergo smaller pulmonary resections or no resections.[4] We report the effectiveness of ECMO in a patient with ARDS following aspiration pneumonia after left pneumonectomy in a patient in the intensive care unit (ICU).

\section{Case Report}

A 74-year-old man had undergone left pneumonectomy for lung cancer 35 years ago, partial laryngectomy for laryngeal cancer 1 year ago, and had been receiving medication for depression because of right lower quadrant abdominal pain for about 1 day. He visited the emergency room and was diagnosed with acute appendicitis. Therefore, he underwent an appendectomy and was discharged on postoperative day 3. Three days later, he visited the emergency room because of operative site pain, fever, nausea, and vomiting. He was diagnosed with postop-

Received on January 20, 2016 Revised on April 1, 2016 Accepted on April 5, 2016

Correspondence to: Yang Gi Ryu, Department of Thoracic and Cardiovascular Surgery, Korea University Guro Hospital, 148 Gurodong-ro, Seoul 08308, Korea Tel: +82-2-2626-1180, Fax: +82-2-866-6377

E-mail: kumgaek@medigate.net

*No potential conflict of interest relevant to this article was reported. erative wound infection and postoperative ileus, for which he was admitted. He underwent an incision and drainage for 15 min in the operating room under local anesthesia.

The patient's oral intake was restricted, and nasogastric tube drainage was maintained because of the ileus. However, he was eager to take only sedatives with sips of water before 

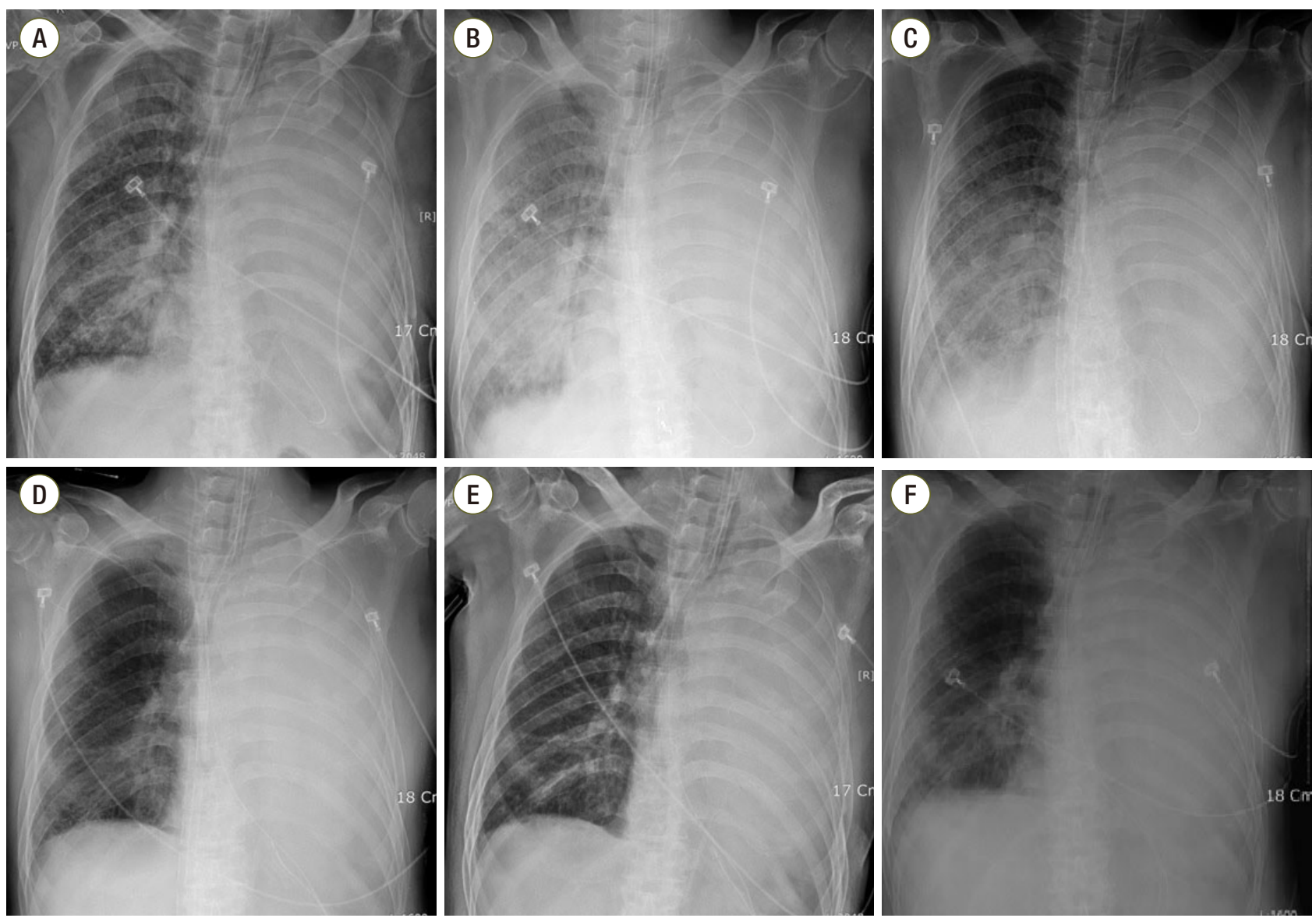

Fig. 1. Serial chest radiographs. (A) Hospital day (HD) number \#1, immediately after aspirating water. (B) HD number \#3, in intensive care unit. (C) On day 2 of extracorporeal membrane oxygenation (ECMO). (D) Improved consolidation in right lung on day 6 of ECMO. (E) 1 hour after weaning from ECMO. (F) HD number \#14, pneumonic infiltration in right lower ling field.

Table 1. Timetable of the ABGA results

\begin{tabular}{lcccccc}
\hline $\begin{array}{l}\text { Hospital day } \\
\text { Result }\end{array}$ & $\mathrm{HD} \mathrm{\# 2}$ & $\begin{array}{c}\mathrm{HD} \mathrm{\# 3} \\
\text { (pre-ECM0) }\end{array}$ & $\begin{array}{c}\mathrm{HD} \# 3 \\
\text { (post-ECM0) }\end{array}$ & $\begin{array}{c}\mathrm{HD} \# 4 \\
\text { (ECM0 \#2) }\end{array}$ & $\begin{array}{c}\mathrm{HD} \# 8 \\
\text { (ECM0 weaning) }\end{array}$ & $\begin{array}{c}\mathrm{HD} \# 56 \\
\text { (ventilator removed) }\end{array}$ \\
\hline $\mathrm{pH}$ & 7.31 & 7.21 & 7.56 & 7.62 & 7.52 & 7.43 \\
$\mathrm{PCO}_{2}(\mathrm{mmHg})$ & 55 & 81 & 31 & 26 & 35 & 54 \\
$\mathrm{PO}_{2}(\mathrm{mmHg})$ & 76 & 62 & 72 & 77 & 129 & 75 \\
$\mathrm{SpO}_{2}(\%)$ & 93 & 86 & 96 & 97 & 99 & 98 \\
\hline
\end{tabular}

ABGA: arterial blood gas analysis; $\mathrm{HD}$ : hospital day; $\mathrm{ECMO}$ : extracorporeal membrane oxygenation; $\mathrm{PCO}_{2}$ : partial pressure of carbon dioxide $\left(\mathrm{CO}_{2}\right) ; \mathrm{PO}_{2}$ : partial pressure of oxygen $\left(\mathrm{O}_{2}\right) ; \mathrm{SpO}_{2}$ : pulse oximetry and the blood oxygen level.

sleeping because of insomnia. That night, the pills stuck in his throat. Hence, he drank water, following which he complained of cough and severe dyspnea. Chest radiography showed diffuse opacity in the right lung (Fig. 1A), and oxygen saturation $\left(\mathrm{SaO}_{2}\right)$ level dropped to $82 \%$. He was transferred to the ICU immediately. Subsequently, endotracheal intubation was performed and a ventilator with volume con- trol mode was used to maintain the inspired oxygen fraction $\left(\mathrm{FiO}_{2}\right)$ at $100 \%$. The tidal volume was $300 \mathrm{~mL}$, positive end-expiratory pressure (PEEP) was $7 \mathrm{cmH}_{2} \mathrm{O}$ and respiratory rate (RR) was 30 . After initiation of mechanical ventilation, the $\mathrm{SaO}_{2}$ level of arterial blood gas increased to $93 \%$. On hospital day (HD) 2, the patient was more stable than on the previous day. $\mathrm{FiO}_{2}$ dropped to $75 \%$ and $\mathrm{SaO}_{2}$ level was 
maintained at over $93 \%$.

However, at dawn on $\mathrm{HD} 3, \mathrm{SaO}_{2}$ dropped to $90 \%$ on the monitor, although $\mathrm{FiO}_{2}$ was $100 \%$, PEEP was $15 \mathrm{cmH}_{2} \mathrm{O}$, and tidal volume was $250 \mathrm{~mL}$; RR remained 25. Blood pressure reached only $125 / 77 \mathrm{mmHg}$ even with high-dose vasopressors (the infusion rate of norepinephrine increased to $8 \mu \mathrm{g} / \mathrm{min}$; these of dobutamine and dopamine were $10 \mu \mathrm{g} /$ $\mathrm{kg} / \mathrm{min}$ and $2.0 \mu \mathrm{g} / \mathrm{kg} / \mathrm{min}$, respectively). Pulse rate also increased to 141 beats/min. Chest anteroposterior radiograph showed aggravation of diffuse opacity and infiltration in the whole right lung (Fig. 1B), and the results of the arterial blood gas analysis (ABGA) showed hypoxemia with severe hypercapnic respiratory acidosis (Table 1). The doctor in charge judged that mechanical ventilation was not sufficient to ventilate oxygen and carbon dioxide. The cardiac surgeon agreed to use VV-ECMO. While preparing for VV-ECMO, epinephrine infusion was started to maintain blood pressure, and a muscle relaxant was administered. The infusion rate of epinephrine was $1 \mu \mathrm{g} / \mathrm{min}$ and that of the muscle relaxant (vecuronium) was $4 \mathrm{mg} / \mathrm{hr}$. Continuous endotracheal suction was performed until ECMO (Maquet Medical Systems USA, Wayne, NJ, USA) was initiated. A 17 French Biomedicus cannula (Medtronic Incorporated, Minneapolis, MN, USA) was inserted in the right femoral vein and was used as the return. A 21 French Biomedicus cannula was inserted in the left femoral vein and used as the drain. Moreover, extracorporeal circulation was started $30 \mathrm{~min}$ after the catheters had been placed. Subsequently, RR and pulse rate were stabilized below 20/min and 100/min respectively just $30 \mathrm{~min}$ utes after extracorporeal circulation began. $\mathrm{SaO}_{2}$ was maintained at over $95 \%$. The ventilator settings were changed to $\mathrm{FiO}_{2}$ of $0.5,250 \mathrm{~mL}$ tidal volume, 12/min RR, and $5 \mathrm{cmH}_{2} \mathrm{O}$ PEEP. The initial oxygen fraction, sweep gas rate, and average flow rate of VV-ECMO were $100 \%, 4 \mathrm{~L} / \mathrm{min}$, and 3,600 $\mathrm{mL} / \mathrm{min}$, respectively. The ABGA results are shown in Table 1. The patient's mean arterial pressure was maintained over at $60 \mathrm{mmHg}$, and we tapered the dose of epinephrine and norepinephrine. Hourly urine output was over $100 \mathrm{~cm}^{3}$. Antibiotics (vancomycin $1 \mathrm{~g}$ b.i.d and metronidazole $500 \mathrm{mg}$ t.i.d) were administered.

The ABGA results in the morning of HD 4 (ECMO day 2) are shown in Table 1. Right upper lobe haziness that had been observed on the chest radiograph had improved. However, lower diffuse consolidation had not improved (Fig.
1C). Vital signs were also stable until the ECMO weaning day. On HD 8, 6 days after the application of ECMO, the patient was weaned from extracorporeal circulation at 10 $\mathrm{AM}$, and could tolerate a conventional ventilator alone (pressure control mode of $45 \% \mathrm{FiO}_{2}, 350 \mathrm{~mL}$ tidal volume, RR of 13/min, $7 \mathrm{cmH}_{2} \mathrm{O}$ PEEP) (Fig. 1D). There were no signs of organ failure or complications following ECMO. However, RR increased up to $30 / \mathrm{min}$, ABGA indicated hypercapnia and respiratory acidosis over time. Then, the ventilator setting was modulated (volume control mode of $45 \% \mathrm{FiO}_{2}, 290$ $\mathrm{mL}$ tidal volume, $\mathrm{RR}$ of $15 / \mathrm{min}, 7 \mathrm{cmH}_{2} \mathrm{O}$ PEEP), and the partial pressure of carbon dioxide $\left(\mathrm{PaCO}_{2}\right)$ was decreased to around $48 \mathrm{mmHg}$. Follow-up chest radiography was performed. (Fig. 1E). Leukocytosis was $22,100 / \mathrm{mm}^{3}(84.6 \%$ neutrophil segment) and C-reactive protein (CRP) level was $83 \mathrm{mg} / \mathrm{L}$.

On HD 9, Pseudomonas aeruginosa was isolated from his bronchial aspiration. Ceftazidime $2 \mathrm{~g}$ t.i.d and clindamycin $600 \mathrm{mg}$ t.i.d were injected. On HD 14, the patient had a fever with a body temperature of more than $38^{\circ} \mathrm{C}$, and pneumonic infiltration in the right lower lung field was observed on radiography (Fig. 1F). Multi-drug resistant Acinetobacter baumannii and methicillin-resistant Staphylococcus aureus were isolated from his bronchial aspiration. Meropenem 500 mg t.i.d, ampicillin/sulbactam 1.5 g q.i.d, and vancomycin $1 \mathrm{~g}$ b.i.d were administered. The white blood cell count was $16,200 / \mu \mathrm{L}$ (84.3\% neutrophil segment) and CRP level was $108 \mathrm{mg} / \mathrm{L}$. the appendectomy site was cleaned and had no signs of infection. After the antibiotics were changed, fever subsided.

On HD 15, the patient's mental status was clear and he was responsive to commands, $\mathrm{SaO}_{2}$ was maintained over $95 \%$, and weaning and extubation were performed. However, the next day the patient complained of breathlessness and $\mathrm{SaO}_{2}$ dropped to $80 \%$; re-intubation was performed and ventilator care was restarted. Subsequently, weaning was attempted consistently.

On HD 21, percutaneous drainage was carried out to relieve pleural effusion of the right lung field. On HD 27, since weaning failed, tracheostomy was performed. Vancomycin was used for 2 weeks and meropenem and ampicillin/ sulbactam were used to treat hospital-acquired pneumonia for 3 weeks. ICU care was continued for 2 months because of high $\mathrm{pCO}_{2}$ and increased RR. 


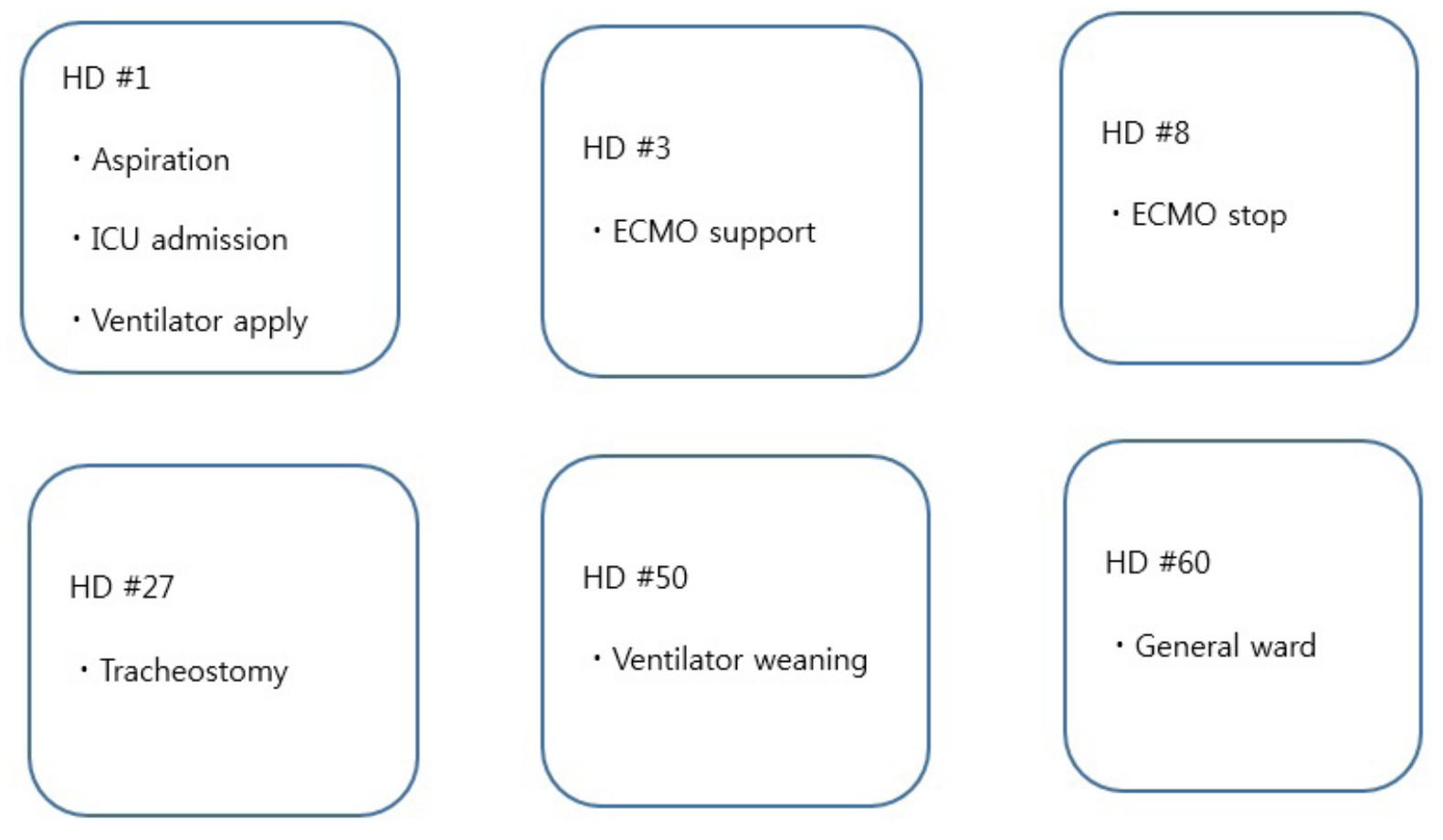

Fig. 2. Brief course of the patient. HD: hospital day; ICU: intensive care unit; ECMO: extracorporeal membrane oxygenation.

From HD 50, ventilator weaning with pressure support mode was started using the pressure control mode. The patient's condition was comparatively tolerable, but $\mathrm{PaCO}_{2}$ reached $50 \mathrm{mmHg}$. On $\mathrm{HD} 56$, the ventilator was removed and a T-piece was connected with $\mathrm{FiO}_{2}$ of $35 \%$. The vital signs were stable. The ABGA results are shown in Table 1. Although $\mathrm{PaCO}_{2}$ was high, the patient did not complain of dyspnea. The white blood cell count was $9,800 / \mu \mathrm{L}(75.1 \%$ neutrophil segment) and CRP level was $20.98 \mathrm{mg} / \mathrm{L}$. On HD 60 , the patient was transferred to the general ward. The brief course of the patient's condition is shown in Fig. 2.

\section{Discussion}

If cases of severe hypoxemia and hypercapnic acidemia do not improve with conventional mechanical ventilator support, ECMO can be used for life support.[3] VV-ECMO is recommended for isolated lung failure without cardiac failure. This technique, which allows optimal gas exchange, has gained consensus as a supportive treatment when conventional mechanical ventilation fails.[5] Nevertheless, VV-ECMO is a procedure associated with high costs and resource utilization.[6] VV-ECMO use should be carefully determined for high-risk patients.

In this case, the patient was $>70$ years old and had undergone a left pneumonectomy for lung cancer and partial laryngectomy for laryngeal cancer. This patient had many risk factors for mortality and morbidity that may not be an indication of ECMO therapy.

There have been cases of VV-ECMO use in ARDS postpneumonectomy. One was a case of multifactorial ARDS (pneumonia, polytransfusion, and fluid overload) after a right pneumonectomy because of blunt chest trauma. The other was a case of left pneumonectomy because of cystic fibrosis. Both cases involved young patients who were 25 and 31 -years -old, respectively.[7,8]

Pneumonectomy results in pulmonary function deficits and decreases exercise capacity.[9,10] Forced vital capacity, forced expiratory volume in $1 \mathrm{~s}$, and diffusion capacity for carbon monoxide are all reduced postsurgery, with a more significant decline. $[9,10]$ Most reports showed that postpneumonectomy patients have diminished exercise tolerance due to mechanical respiratory limitation, low ventilator capacity, reduced breathing reserve, and dyspnea without significant differences between right or left lung removal.[11-15] Pneumonectomy is 
associated with several anatomical changes within the thoracic cavity that may reduce maximal cardiac output and attenuate heart function.[10] Most patients can maintain nearnormal life in activities of daily living, but the conditions such as pneumonia or ARDS are fatal postpneumonectomy or the abovementioned reasons.[16]

Aspiration pneumonia is treated with antibiotics. ECMO is just a supportive unit that can be used to control lung functions, even in pneumonectomy patients. Hospitalacquired infections are still most common among patients who had been recently hospitalized and infections include those by gram-negative bacteria such as Pseudomonas aeruginosa and Klebsiella pneumoniae as well as methicillinresistant Staphylococcus aureus. Piperacillin/tazobactam or imipenem/cilastatin plus vancomycin would be appropriate for treatment of such infections.[17] Further, appropriate antibiotic regimens must be chosen according to sputum culture results. In this case, we prescribed vancomycin and metronidazole at first. However, there were no grampositive cocci on culture, of a single on the sputum stain. The regimens were inappropriate, and pneumonia might be aggravated. The antibiotics were changed to ceftriaxone and clindamycin to treat Pseudomonas in the sputum after the infecting bacteria were identified. After 2 weeks, the patient had fever and the haziness of the right lung was enhanced. The medication was changed to meropenem and ampicillin/ sulbactam to treat multi-drug resistant Acinetobacter baumannii.

In conclusion, the medical team could consider ECMO to treat aspiration pneumonia in postpneumonectomy patients or other high-risk patients. Once aspiration pneumonia occurs, the respiratory system can develop pneumonitis, pneumonia, and acute lung injury, including ARDS. If severe hypoxemia and hypercapnia occurs and optimal gas exchange cannot achieved by conventional mechanical ventilation, extracorporeal life support can have survival benefits even in postpneumonectomy.

\section{ORCID}

Jangwhan Jo

http://orcid.org/0000-0001-7242-2569

\section{References}

1) Engelhardt T, Webster NR: Pulmonary aspiration of gastric contents in anaesthesia. Br J Anaesth 1999; 83: 453-60.

2) Warner MA, Warner ME, Weber JG: Clinical significance of pulmonary aspiration during the perioperative period. Anesthesiology 1993; 78: 56-62.

3) Kim N, Kim KH, Kim JM, Choi SY, Na S: Early extracorporeal membrane oxygenation for massive aspiration during anesthesia induction. Korean J Crit Care Med 2015; 30: 109-14.

4) Harpole DH, Liptay MJ, DeCamp MM, Jr., Mentzer SJ, Swanson SJ, Sugarbaker DJ: Prospective analysis of pneumonectomy: risk factors for major morbidity and cardiac dysrhythmias. Ann Thorac Surg 1996; 61: 97782.

5) Diaz JV, Brower R, Calfee CS, Matthay MA: Therapeutic strategies for severe acute lung injury. Crit Care Med 2010; 38: 1644-50.

6) Enger T, Philipp A, Videm V, Lubnow M, Wahba A, Fischer M, et al: Prediction of mortality in adult patients with severe acute lung failure receiving venovenous extracorporeal membrane oxygenation: a prospective observational study. Crit Care 2014; 18: R67.

7) Saueressig MG, Schwarz P, Schlatter R, Moreschi AH, Wender OC, Macedo-Neto AV: Extracorporeal membrane oxygenation for postpneumonectomy ARDS. J Bras Pneumol 2014; 40: 203-6.

8) Martucci G, Panarello G, Bertani A, Occhipinti G, Pintaudi S, Arcadipane A: Veno-venous ECMO in ARDS after post-traumatic pneumonectomy. Intensive Care Med 2013; 39: 2235-6.

9) Powell ES, Pearce AC, Cook D, Davies P, Bishay E, Bowler GM, et al: UK pneumonectomy outcome study (UKPOS): a prospective observational study of pneumonectomy outcome. J Cardiothorac Surg 2009; 4: 41.

10) Deslauriers J, Ugalde P, Miro S, Deslauriers DR, Ferland $\mathrm{S}$, Bergeron $\mathrm{S}$, et al: Long-term physiological consequences of pneumonectomy. Semin Thorac Cardiovasc Surg 2011; 23: 196-202.

11) Smulders SA, Smeenk FW, Janssen-Heijnen ML, Postmus PE: Actual and predicted postoperative changes in lung function after pneumonectomy: a retrospective 
analysis. Chest 2004; 125: 1735-41.

12) Deslauriers J, Ugalde P, Miro S, Ferland S, Bergeron $\mathrm{S}$, Lacasse $\mathrm{Y}$, et al: Adjustments in cardiorespiratory function after pneumonectomy: results of the pneumonectomy project. J Thorac Cardiovasc Surg 2011; 141: 7-15.

13) Nugent AM, Steele IC, Carragher AM, McManus K, McGuigan JA, Gibbons JR, et al: Effect of thoracotomy and lung resection on exercise capacity in patients with lung cancer. Thorax 1999; 54: 334-8.

14) Larsen KR, Svendsen UG, Milman N, Brenøe J, Petersen BN: Cardiopulmonary function at rest and during exercise after resection for bronchial carcinoma. Ann Thorac Surg 1997; 64: 960-4.

15) Pelletier C, Lapointe L, LeBlanc P: Effects of lung resection on pulmonary function and exercise capacity. Thorax 1990; 45: 497-502.

16) Vainshelboim B, Fox BD, Saute M, Sagie A, Yehoshua L, Fuks L, et al: Limitations in exercise and functional capacity in long-term postpneumonectomy patients. J Cardiopulm Rehabil Prev 2015; 35: 56-64.

17) Anand S: Aspiration pneumonitis and pneumonia. 2015 [2015 April]. Available from http://emedicine.medscape.com/article/296198-overview. 